Urol Res (1991) 19:277-280

\title{
Single potential analysis of cavernous electrical activity*
}

\author{
C. G. Stief, W. F. Thon, M. Djamilian, W. de Riese, K. W. Fritz, E. P. Althoff, and U. Jonas \\ ${ }^{1}$ Departments of Urology and Anesthesiology, University Clinic, Hannover, FRG
}

Accepted: $\Lambda$ pril 1, 1991

Summary. Recording of cavernous electric activity was performed in 178 patients with erectile dysfunction and in 37 normal patients. In $34 / 37$ normal patients, potentials of a uniform shape were recorded during flaccidity: At cut-off frequences of $0.5-500 \mathrm{~Hz}$, the length was $8-18$ (mean 12.8, SD 2.8), the amplitude 250-750 (mean 444, SD 109) $\mu \mathrm{V}$, and the polyphasity $8-22$ (mean 13.8 , SD 3.3 ). In impotent patients with upper motor neuron lesions or peripheral lesions, specific types of potentials were observed. In 11/14 impotent patients with insulin-dependent diabetes for over 20 years and clinical findings of cavernous myopathy, potentials showed low amplitude, irregular shape, and slow depolarizations. In $51 \%$ of the consecutive impotent patients, abnormal findings of cavernous electric activity were recorded. Our clinical study suggests that single potential analysis of cavernous electric activity (SPACE) may be useful in the diagnosis of cavernous autonomic neuropathy and cavernous smooth muscle myopathy.

Key words: Erectile dysfunction - Autonomic innervation - Cavernous electric activity - Diagnosis of autonomic dysfunction

During the past decade, the diagnosis of erectile dysfunction was significantly improved by the introduction of the intracavernous injection of vasoactive drugs $[1,9,10,19$, 20]. This induces cavernous hemodynamic changes similar to the physiologic erection $[8,14]$, enabling a more accurate diagnosis in impotent patients.

To elucidate possible neurogenic lesions, the somatoscnsory penile innervation was mostly examined due to the lack of tests for the cavernous autonomic nervous system. Measurement of the latency of the bulbocavernous reflex (BCR-L) was usually performed $[6,12]$, but recent publications cast some doubts on the relevance of this procedure for autonomic neuropathy [7]. Furthermore, tests for the sympathetic innervation [3] or the vibratory

\footnotetext{
* This study was supported by a grant of the Deutsche Forschusagsgemeinschaft (Sti 96/2-1)

Part of this paper was presented at the 10th Symposium of the Association for Experimental Urology of the German Urological
} Society, June 21-23, 1990, Munich, FRG system were suggested, but their clinical relevance is yet to be established.

Gerstenberg and Wagner were the first to approach this major drawback in the diagnosis of erectile dysfunction when they suggested the registration of cavernous smooth muscle activity $[4,16,17]$. In the following we describe the registration of cavernous electric activity with a different data processing than that published by them. Whereas Gerstenberg et al. interpreted their recordings according to the existence or the lack of electric activity during erection, we dispersed the electric activity recordings on a wider time scale. This enables a more specific interpretation of the electrical potentials of the cavernous smooth muscles during flaccidity, thus possibly allowing a minimal invasive diagnosis of autonomic cavernous neuropathy and of cavernous smooth muscle degeneration.

\section{Patients and methods}

Since May 1989 and the introduction of single porential analysis of cavernous electric activity (SPACE) into our routine diagnostic procedures, 154 consecutive patients with erectile dysfunction were cvaluated multidisciplinarily in our impotence clinic. In all patients, the minimum duration of impotence was one year. Our standard diagnostic procedures included history and physical examination, sexual history and psychometry, laboratory blood tests including testosterone and prolactin levels, Doppler of the penile arteries [5], standardized pharmacotesting [15], Rigiscan real-time monitoring during visual sexual stimulation (VSS) before and after intracavernous injection of $3 \mathrm{mg}$ papaverine and $0.1 \mathrm{mg}$ phentolamine, and SPACE. When indicated [15], pharmaco-cavernosometry and $\mathrm{Ca}-$ vernography or phalloarteriography were done. Furthermore, 37 patients from our urological ward with normal crectile function underwent SPACE. Another 24 patients with erectile dysfunction were referred from other departments (especially the diabotes clinic) or centers especially for SPACE evaluation.

Some patients suffered from an insulin-dependent diabetes (14 for more than 20 years), 11 had primary erectile dysfunction, 7 chronic renal failure, and 1 multiple sclerosis. Three patients had a cystoprostatectomy, 4 a radical prostatectomy, 3 an abdominoperineal extirpation of the rectum. and 6 a completc traumatic lesion of the spinal cord above Th11. Two patients had posttraumatic impotence, 8 intervertebral disc prolapse, and 2 a hemipelvectomy. Three had undergone anterior extirpation of the rectum, 2 had a neurologically proven peripheral polyneuropathy, I a severe hypothyroidism, and 1 a cauda syndrome after meningoencephalitis.

For the first 71 patients, cut-off frequencies wre $2-2,000 \mathrm{~Hz}$, for the following $0.5-500 \mathrm{~Hz}$ was used (as well as $2-500 \mathrm{~Hz}$ for the next 32 patients). During the examination the pationts remained in a 


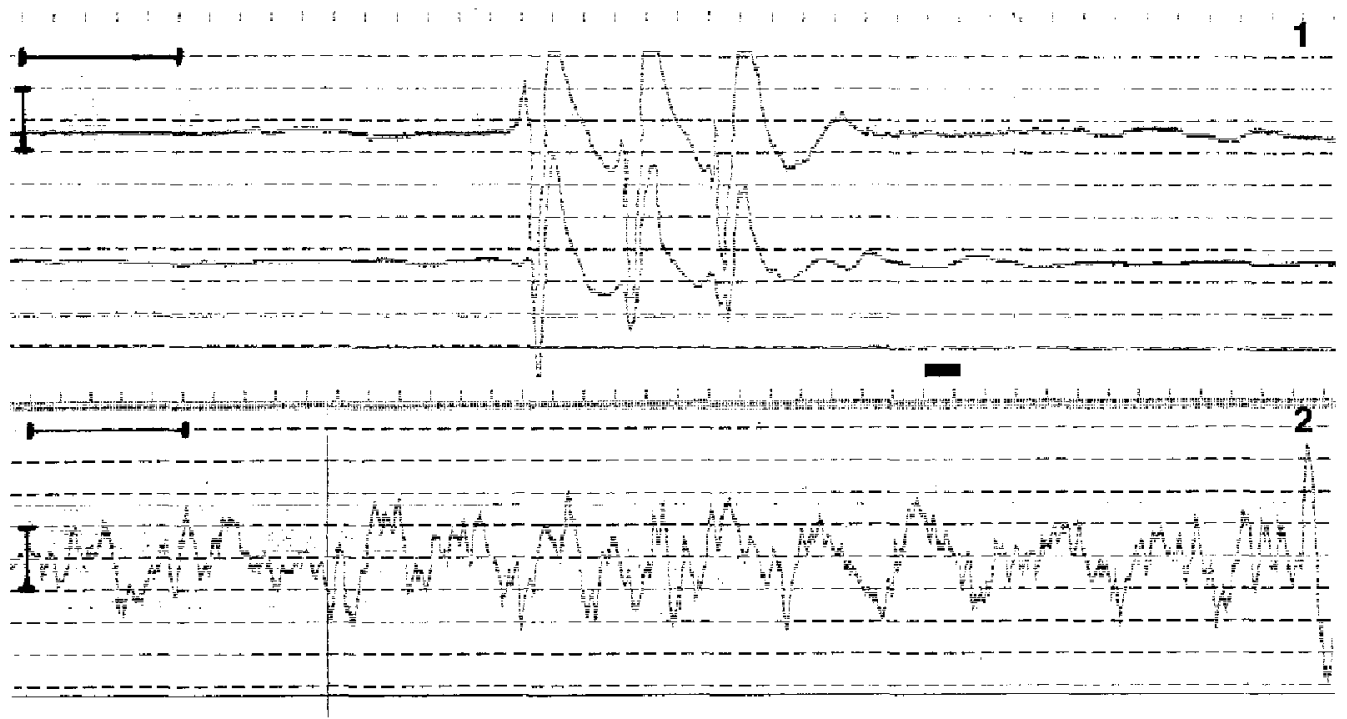

Fig. 1. Simultaneous recording of cavernous electric activity in both cavernous bodies shows synchronization of cavernous clectric activity in the normal man

Fig. 2. Recording of a 29 year-old patient with varicocele 1 h prior to surgery. The horizontal bar is $5 \mathrm{~s}$, the vertical bar $100 \mu \mathrm{V}$ sitting position, a coaxial needle electrode (Dantec $9013 \mathrm{~L}$; length 4 $\mathrm{cm}$, surface of the tip $0.07 \mathrm{~mm}^{2}$ ) was inserted laterally into the cavernous body. The electrode was pushed forward into the proximal cavernous body until its tip was located in the center. The potentials were processed by an electrophysiological unit (modified Dantec Neuromatic 2000, Copenhagen, Denmark; Wiest Space Recorder, Munich, FRG). The signals were displayed continuously on a screen monitor as well as simultaneously recorded; paper speed was $5 \mathrm{~mm} / \mathrm{s}$. The upper cut-off frequency of the Neuromatic thermowriter was $10 \mathrm{KHz}$, of the Wiest thermowriter $100 \mathrm{~Hz}$. Amplification was mostly at $50 \mu \mathrm{V} /$ unit.

\section{Examination}

Because all normal patients showed abnormal potentials up to 15 min after introduction of the needle electrode (which means that these potcntials were not recorded afterwards and possible reflect. potentials induced by injury to smooth muscle cells by the electrode), SPACE evaluation was started 20 min after needle electrode administration. After registration of cavernous electric activity during flaccidity for $25 \mathrm{~min}$ andiovisual sexual stimulation (AVSS) was applied for another $25 \mathrm{~min}$, with the examiner leaving the room. At the end of AVSS, the examiner evaluated the erectile response by inspection, palpation, and interrogation. Recording was continucd for another 10 min. During flaccidity, the patient was advised to close his eyes and relax.

Usually, the nccdle electrode was inserted into the left cavernous body. To evaluate whether the cavernous electric activity is synchronous in different areas of the penis, 2 needles were inserted into each cavernous body or in 1 cavernous body proximally and distally in more than 50 patients.

\section{Results}

Electric activity of the cavernous smooth muscles could not be registered in 1 impotent and 2 normal patients. When we changed the lower cut-off frequently to $0.5 \mathrm{~Hz}$, in the second normal patient with no recorded activity (overall patient No.71), potentials were easily recorded. Starting with this patient, we therefore chose $0.5 \mathrm{~Hz}$ as the lower cut-off frequency. Reducing the cut-off frequency from 2 to $0.5 \mathrm{~Hz}$ resulted in an increase in amplitude of about $80 \%-250 \%$.
In 34/36 normal patients with recorded activity, the potentials were similar. The potentials started with a positive depolarization or with a short-lasting negative, followed by a positive depolarization. At cut-off frequencies of $2-2,000 \mathrm{~Hz}$, the length of the potentials was $3-12$ (mean 0.5; SD 0.3) s, the amplitude was 60-250 (mean 153; SD 31) $\mu \mathrm{V}$, polyphasity was $5-11$ (mean 8.5; SD 0.3). At cut-off frequencies of $0.5-500 \mathrm{~Hz}$, the length was $8-18$ (mean 12.8, SD 2.8) s, the amplitude 250-750 (mean 444, $\mathrm{SD} 109) \mu \mathrm{V}$, and the polyphasity $8-22$ (mean 13.8 , SD 3.3 ). The shape of the potentials was very uniform for the same individual, although the frequency varied considerably, depending on the degree of relaxation of the patient. Frequency was 0.6-2.6 potentials/min. Sirnultaneous recording of cavernous electric activity in both cavernous bodies showed synchronization of the potentials (Fig. 1).

To evaluate a possible influence of stress on the cavernous elcetric activity, SPACE was performed about. $1 \mathrm{~h}$ before surgery in 2 normal patients. In both patients, a wavelike electrical activity with small potentials in these waves, but no specific bigger potentials was recorded (Fig. 2).

All normal patients consented to AVSS. Comparing the potentials during flaccidity and tumescence or erection, a uniform change could be observed. With increasing tumescence and rigidity, an increase in frequency of the potentials with simultaneous decrease in amplitude and polyphasity was seen (Fig. 3). During full erection, potentials were recorded in all patients. In contrast to this, no potentials (electrical silence) were recorded after intracavernous injection of papaverine and phentolamine or prostaglandin (PGE 1). In the patients with a presumable lesion of the upper motorneuron (complete traumatic spinal cord injury above T 11), potentials with a duration of $28 \mathrm{~s}$ to over $2 \mathrm{~min}$ were recorded. The amplitude of the potentials as well as the time between the passages of the baseline was comparable with those recorded in normal patients.

In the patients with a presumable lesion of the peripheral autonomic nerve (after cystoprostatectomy or abdominoperineal extirpation of the rectum), short po- 


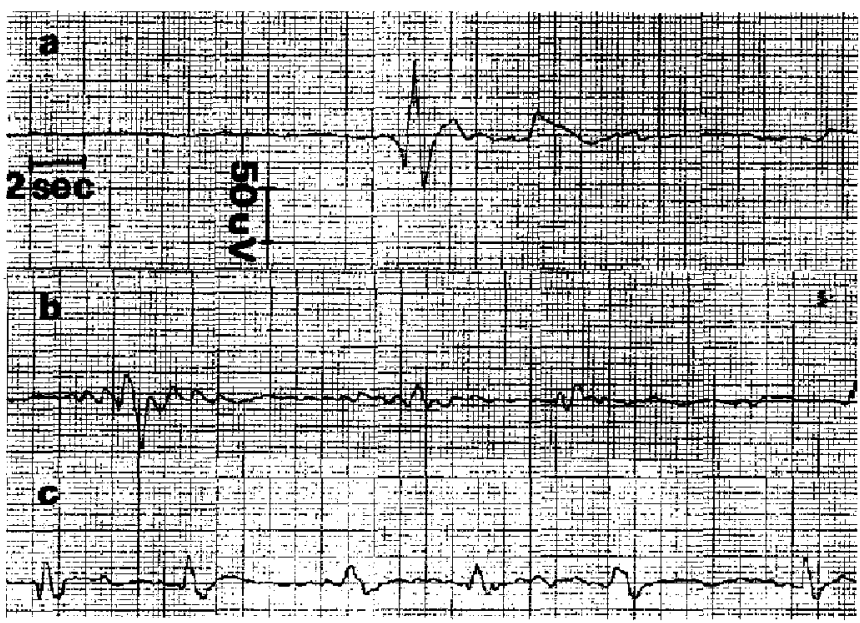

Fig. 3a-c. The upper tracing (a) shows the recording during flaccidity in a 22 -year-old normal patient (1 large potential), the medium tracing (b) shows the electrical activity during tumescence to audiovisual sexual stimulation. The lower tracing (c) shows the electrical activity during an almost full erection. Cut-off frequencies are $2-2,000 \mathrm{~Hz}$

Fig. 4. Some 13 years after nonnerve-sparing radical prostatectomy, SPACE shows desynchronized pathological cavernous electric activity in a 63-year-old parient. Upper tracing in the right, lower in the left cavernous body; the horizontal bar is $5 \mathrm{~s}$, the vertical bar $100 \mu \mathrm{V}$; cut-off frequencies are $0.5-100 \mathrm{~Hz}$

Fig. 5. One year after radical prostatectomy, SPACE shows normal (only in the lower recording = left cavernous body) as well as abnormal (asynchronous in both cavernous bodies) potentials in a 65-year-old impotent man. The horizontal bar is $5 \mathrm{~s}$, the vertical bar $100 \mu \mathrm{V}$ tentials with a significantly reduced amplitude were recorded. In these patients, short potentials with a fast convex phase of depolarization and a slower repolarization phase of concave shape ("whip") were seen frequently (Fig. 4). In $2 / 3$ of the patients after cystoprostatectomy and $1 / 3$ of the patients after extirpation of the rectum, normal potentials and pathological electric activity were recorded (Fig. 5). Of the patients after radical prostatectomy showed normal electric activity of the cavernous smooth muscles, whereas $2 / 4$ showed normal as well as abnormal potentials. No patient showed completely abnormal electric activity (as $1 / 3$ of the patients after cystoprostatectomy) in this group.

In $11 / 14$ of the patients with insulin-dependent diabetes mellitus (duration over 20 years), multidisciplinary examination showed signs highly suspective for cavernous smooth muscle degeneration [13]. On palpation, the penis of these patients felt much smaller compared with other patients. All patients had only a poor response to the intracavernous injection of vasoactive drugs and showed extensive venous leakage upon cavernosometry and cavernography study with SPACE, these patients showed potentials of low amplitude, irregular shape, and slow depolarization (Fig. 6).

In 2 patients with erectle dysfunction, the recordings could not be interpreted due to wavelike bascline activity.

Fig. 6. Recordings in a 32-year-old patient with insulin-dependent diabetes of over 21 years, duration show potentials of low amplitude and slow depolarizations (electrodes in both cavernous bodies). The horizontal bar is $5 \mathrm{~s}$, the vertical bar $100 \mu \mathrm{V}$
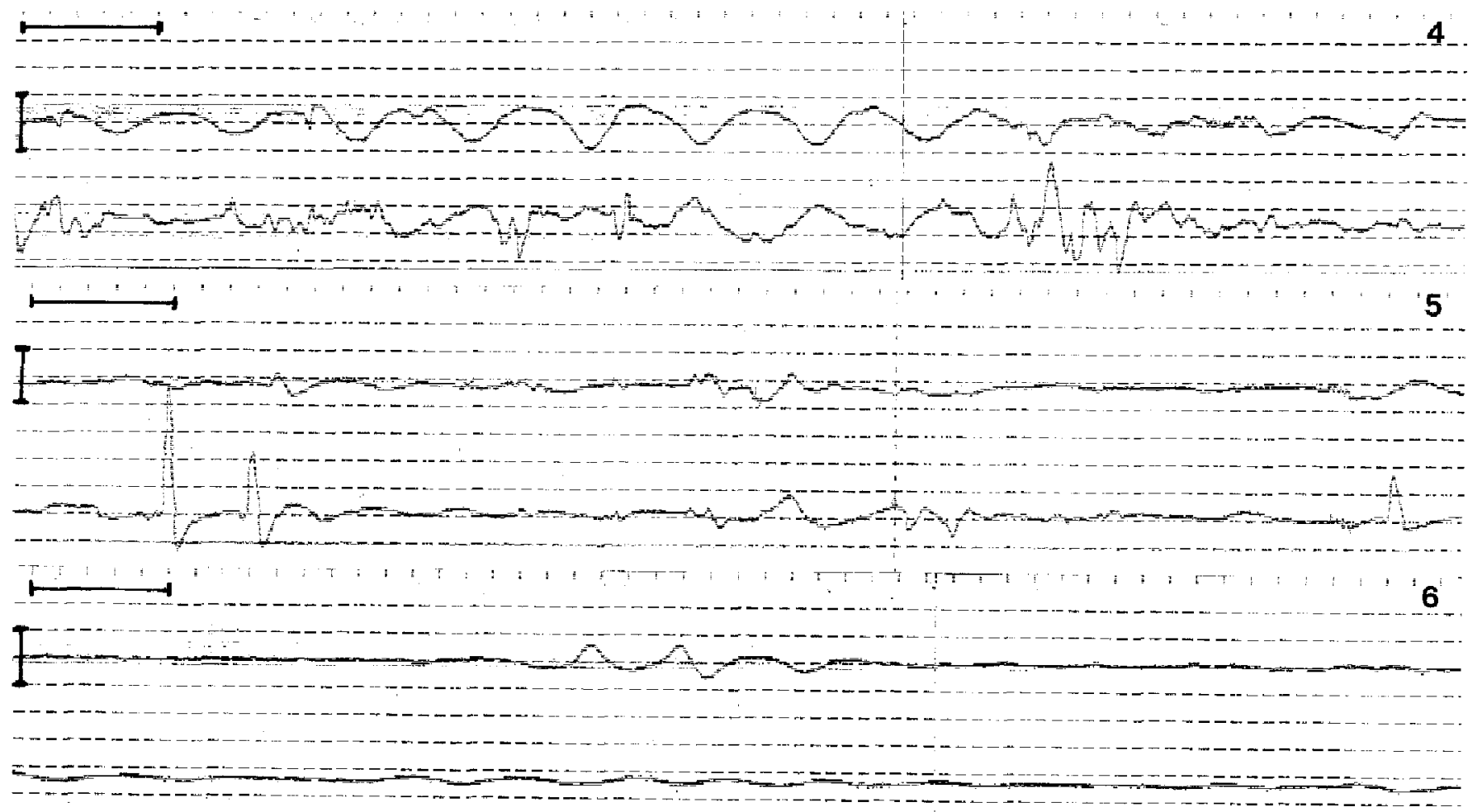


\section{Discussion}

Our findings show that the electric potentials of cavernous smooth muscle activity can be recorded. The reproducible recordings and the similarity of the potentials in normal patients as well as the different recordings during full erection to AVSS on the one hand and to intracavernous injection of vasoactive drugs on the other strongly suggest that the recordings are not artifacts. The potentials recorded in normal patients are similar to smooth muscle potentials recorded in other smooth muscle organs in other species [15].

The patients in the groups with defined neurologic lesions were mostly of younger age and had therefore, presumably, a good cavernous smooth muscle. All but one of these patients achieved full erection with the intracavernous injection of $0.5 \mathrm{ml}$ papaverine $(15 \mathrm{mg} / \mathrm{ml})$ and phentolamine $(0.5 \mathrm{mg} / \mathrm{ml})$ or less. This full erectile response to a minimal dose of vasoactive drugs [13] strongly suggests intact penile hemodynamics with subsequent intact cavernous smooth muscles in these patients. Therefore, the alteration in the recording of the cavernous electric activity here is most probably due to the neurologic lesions of the patients and not to smooth muscle degeneration.

In the patients with insulin-dependent diabetes to over 20 years and signs of extensive cavernous smooth muscle degeneration in the clinical work-up, significant changes of cavernous electric activity were found. Desynchronization of cavernous electric activity seems to indicate peripheral autonomic dysfunction, whereas the low amplitude and the slow depolarization of the potentials are suggestive for cavernous smooth muscle degeneration. This assumption correlates well with the electron microscopic findings in patients with venous leakage [11].

Our findings in normal patients suggest that during flaccidity, the contractions of the cavernous smooth muscle cells are synchronized by the sympathetic tone. This results in a potential of high amplitude and long duration that can be simultancously rccorded in different areas of both cavernous bodies. During physiological erection, the sympathetic tone is dramatically reduced, resulting in a nonsynchronization of the contractions of the SMCs. This results in potentials of decreased amplitude and length but in an increase in frequency.

Our study showed 51 abnormal SPACE findings in 154 consecutive patients with erectile dysfunction. This rate seems surprisingly high compared with about $10 \%$ neurogenic factors in the etiology of impotence in the literature. Nevertheless, it must be taken into account that this rate was mostly based on the measurement of the BCR-L. Comparing the possibility of damage of the autonomic (possibly diagnosed by SPACE) and of the somatosensory system (diagnosed by BCR-L), it is well-known that damage of the autonomic system may occur much earlier in time [2]. Furthermore, electron microscopic study showed pathologic findings of the cavernous innervation in $40 \%$ of the patients [18].

In all patients, the diagnosis of abnormal autonomic innervation could be made by SPACE without AVSS, whereas synchronous recording with 2 needles in each cavernous body facilitated the diagnosis. We think that SPACE may be a minimal invasive and reproducible dianostic method to evaluate autonomic cavernous innervation. A diagnosis of cavernous smooth muscle degeneration by SPACE seems possible. Further comparative studies with electron microscopic controls will evaluate the correlation of our interpretation of SPACE with the morphological findings.

\section{References}

1. Brindley GS (1983) Cavernosal alpha-blockade: a new technique for investigating and treating erectile impotence. $\mathrm{Br} J$ Psychiatry $143: 332$

2. Ellenberg $M$ (1980) Development of urinary bladder dysfunction in diabetes mellitus. Ann Intern Med 92:321-324

3. Ertekin C, Ertekin N, Almis S (1989) Autonomic sympathetic nerve involvement in diabetic impotence. Neurourol Urodyn $8: 589$

4. Gerstenberg TC, Nordling J, Hald $H$, Wagner G (1989) Standardized evaluation of erectile dysfunction in 95 consecutive patients. J Urol 141:857

5. Jevtich MJ (1983) Non-invasive vascular and neurogenic tests in use for evaluation of angiogenic impotence. Inter Angio 3:964

6. Laivas JG, Zayed AA, Labib KB (1981) The bulbocavernous rellex in urology. J Urol 126:197

7. Lavoisier P, Proulx J, Courtois F, Carful F (1989) Bulbocavernous reflex. J Urol 141:311

8. Lue TF, Takamura T, Schmidt RA, Tanagho EA (1983) Hemodynamics of erection in the monkey. J Urol 130:1237

9. Lue TF, Hricak H, Marich KW, Tanagho ET (1985) Evaluation of arteriogenic impotence with intracorporal injection of papaverine and the duplex ultrasound scanner. Semin Urol 3:43

10. Lue TF, Hricak H, Schmidt RA, Tanagho EA (1986) Functional evaluation of penile veins by cavernosography in papaverineinduced crection. J Urol 135:479

11. Persson C, Diederichs W, Lue TF, Ven TS, Fishman I, Lin PH, Tanagho ET (1989) Correlation of altered ultrastructure with clinical arterial evaluation. J Urol 142:1462

12. Siroky MB, Sax DS, Krane RJ (1979) Sacral signal tracing. J Urol 122:661

13. Stief CG, Bähren W, Gall H, Scherb W (1988) Functional evaluation of penile hemodynamics. J Urol 139:734

14. Tejada de S, Goldstein I, Krane RJ (1988) Local control of penile erection. Urol Clin $N$ Am 15:9

15. Wagner $G$ (1976) Contractility of myometrial transplants. In: Coutinhu EM, Fuchs F (eds) Physiology and genetics of reprom duction, part B. Plenum, New York

16. Wagner $G$, Gerstenberg $T$ (1988) Human in vivo studies of electrical activity of corpus cavernosum. J Urol 139:327 A

17. Wagner G, Gerstenberg T, Levin RJ (1989) Electrical activity of corpus cavernosum during flaccidity and erection of the human penis. J Urol 142:723

18. Wetterauer $\mathrm{U}$, Stief CG, Kulvelis F, Staubesand J, Sommerkamp H (1990) The electron microscopic ultrastructure of cavernous tissue in erectile dysfunction. J Urol 143:509 A

19. Virag R (1982) Intracavernous injection of papaverine for erectile failure. Letter to the editor Lancet II:938

20. Zorgniotti AW, Lefleur RS (1985) Auto-jnjection of the corpus cavernosum with a vasoactive drug combination for vasculogenic impotence. J Urol 133:39

Dr. Christian G. Stief

Urologische Klinik

Medizinische Hochschule

Konstanty-Gutschow-Strasse 8

W-3000 Hannover 61

Federal Republic of Germany 